\title{
Thermal Analysis by Conduction Convection and Radiation in a Power Cable
}

\author{
Aluru Divya Teja ${ }^{1}, \mathrm{~K}_{\text {Rajagopala }}^{2}$ \\ ${ }^{1}$ M.Tech student in EEE Department, NITK, Surathkal, India \\ ${ }^{2}$ Associate Professor in EEE Department, NITK, Surathkal, India
}

\begin{abstract}
In this present paper different models are implemented to study the thermal effects at various installation conditions. When a cable is installed in air, solar and wind effects are taken into consideration to know the effect on cables. The heat generated in the cable that is buried in trenches dissipates heat through the backfill material surrounding the cable. The heat generation decreases with the increase in thermal conductivity of the moist soil. The effect of steam pipe crossing over a cable underground causes the moisture migration from the soil. The results are obtained in COMSOL MULTIPHYSICS software which solves the equations based on finite element method.
\end{abstract}

Keywords: solar and wind effects, backfill material, COMSOL-MULTIPHYSICS software, moisture migration

\section{Introduction}

Power transmission through cables is much required in urban areas to reduce the outages. It is used to power all the equipments inside the buildings and houses by passing through conduits. Current flowing through the cables is based on the load connected to it. This causes losses in the conductor based on the skin, proximity effects along with the losses that occur in the insulation and the sheath. This develops the temperature which is dissipated to the surrounding to operate the cable within safety limit [1]. Heat dissipation in a cable depends upon the installation conditions, spacing between conductors and ambient temperature. Here we consider a cable which is installed in air and other one which is buried in soil. With increase in heat transfer coefficient the rate of heat dissipation increases resulting in less cable temperature [2].The ambient temperature and air velocity can influences the cables heat transfer coefficient. The maximum current carrying capacity depends on all factors that cause the variation in heat dissipation. It follows the finite element method to estimate the thermal effect on cables. When the cables are buried directly in trenches the area is filled layer by layer with the materials that are required to increase the heat dissipation rate. The bottom layer of the trench is filled with fine sand and then filled with moist soil [3]. Moisture migration takes place due to the thermal effect in the underground cable. The rate of heat dissipation is more by decreasing the thermal conductivity of bedding than that of the backfill soil [4]. Oil and gas filled cable are used to avoid the formation of voids which are filled by the pressure of the liquid or gas inside the cable. The heat generated is absorbed by the oil and it also provides electrical insulation for the cable. Sf6 gas is used because of its high dielectric strength which can be operated even at $500 \mathrm{kV}$. The heat flux distribution shown with various fillers gives appreciable results for Sf6 gas insulated cables.

\section{THERMAL ANALYSIS}

\section{Theory}

There are three mechanisms by which heat is dissipated from the cable. They are conduction, convection and radiation.

\subsection{Heat Transfer By Conduction:}

The heat transfer from the cable is by means of conduction when the cable is buried directly in the ground. Differential equation to calculate the temperature is [5]

$$
-\nabla .(\mathrm{K} \nabla \mathrm{T})=Q+h\left(T_{a m b}-\mathrm{T}\right)
$$

Where $\mathrm{T}_{\mathrm{amb}}$ is ambient temperature (Kelvin), $\mathrm{T}$ is the conductor temperature (Kelvin), $\mathrm{k}$ is thermal conductivity $(\mathrm{W} / \mathrm{m} . \mathrm{k}), \mathrm{h}$ is the heat transfer coefficient $\left(\mathrm{W} / \mathrm{m}^{2} . \mathrm{k}\right)$ and $\mathrm{q}$ is the heat source $(\mathrm{W} / \mathrm{m})$.

\subsection{Heat Transfer By Convection And Radiation:}

Convection and radiation heat transfer occurs when the cable is installed in air. Thus the heat dissipation occurs from the cables surface to the surrounding atmosphere. These are influenced by the atmospheric factors like wind effect and solar radiation which reduces the cable ampacity. The effect of solar radiation is to be treated as a heat source.

The differential equation is given by

$$
Q=h\left(T-T_{a m b}\right)
$$


Where $\mathrm{h}$ is the heat transfer coefficient that varies between 2 and 25 for free convection and between 25 and 250 for forced convection $\left(\mathrm{W} / \mathrm{m}^{2} \cdot \mathrm{k}\right)$.

\section{Proximity Effect:}

It causes the increase in current density in the cables having less spacing. This in turn causes losses that produces heat which reduces the current carrying capacity of the cables. As the middle cable is influenced by the other two cables near to it so it will develop higher losses and high temperature.

\section{Modeling parameters}

All the models are implemented in COMSOL MULTIPHYSICS software. This softwares gives the results based on finite element approach. Here we use two modules to show all the thermal and magnetic effects [6]. They are 1) conduction and convection module 2) AC power electromagnetic module The parameters specified for a cable are current carrying capacity, ambient air temperature, heat transfer coefficient, thermal conductivity and solar heat source.

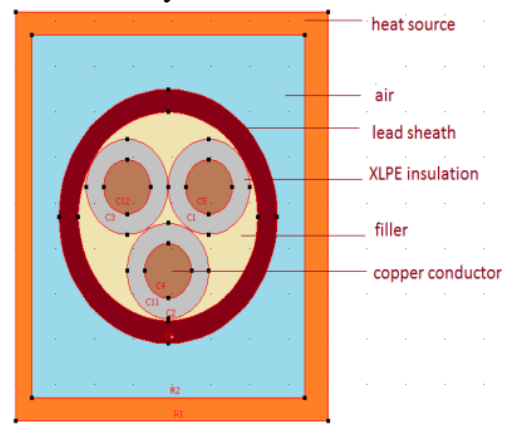

Fig.1 : 3-core cable installed in air

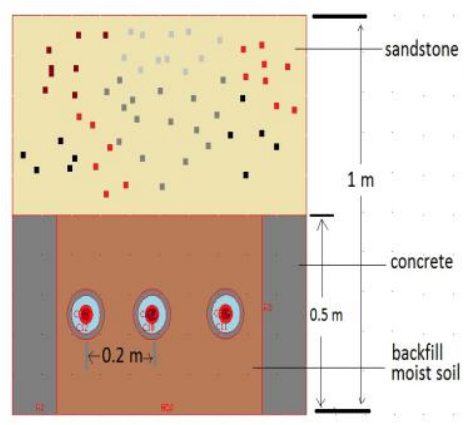

Fig.2 : cables laid in trench

In Fig. 13 -core cable modeled is installed in air has the effects of solar radiation and wind.

The wind effect is considered with the wind inlet velocity of $25 \mathrm{~m} / \mathrm{s}$ is applied to the left boundary. Then by assuming the right boudary as low density region where the wind velocity is set at $10 \mathrm{~m} / \mathrm{s}$. so now the wind flowing from high density region to low density region. The solar radiation effect is considered as an average of $300 \mathrm{~W} / \mathrm{m}^{2}$ which is applied as heat source to the outer boundaries which is a very low value.

In Fig. 2 cables are buried directly in the trenches underground. When the cables are laid in trenches the backfill material should be selected in such a way that they are free from all inorganic matter,stones etc. Then for the dissipation of the heat thermal resistivity of the soil should be less. The thermal resistivity of the material is tested in laboratory and then fine sand is filled in the $1^{\text {st }}$ layer till $0.20 \mathrm{~m}$. Then cables are laid with spacing of $0.20 \mathrm{~m}$ between each cable to reduce the thermal effects on each other. Then another layer of moist soil is filled in the trench till $0.50 \mathrm{~m}$. This composition is surrounded by concrete with $5 \mathrm{~mm}$ thickness. Then the bricks or stones are provided in the top layer and fill it with the soil dug from that place.

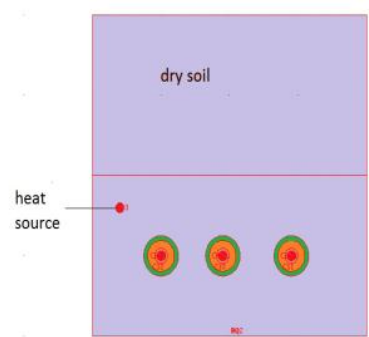

Fig 3: heat source effect on the cables underground.

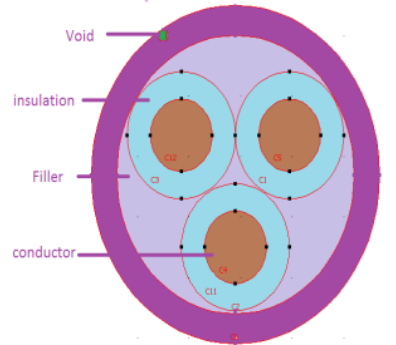

Fig 4: 3-core cable with void

Table-I: Cable Parameters

\begin{tabular}{|c|c|c|c|c|c|c|c|c|c|}
\hline Materials & Copper & XLPE & Lead & Air & $\begin{array}{l}\text { Sand } \\
\text { stone }\end{array}$ & $\begin{array}{l}\text { Moist } \\
\text { soil }\end{array}$ & $\begin{array}{l}\text { Concrete } \\
\text { dense }\end{array}$ & Mineral oil & $\begin{array}{l}\text { SF6 } \\
\text { gas }\end{array}$ \\
\hline $\begin{array}{c}\text { Thermal conductivity } \\
(\mathrm{W} /(\mathrm{m} . \mathrm{k}))\end{array}$ & 400 & 0.38 & 34 & 0.024 & 1.7 & $0.25-2$ & $1.0-1.8$ & 0.46 & 0.0136 \\
\hline Density $\left(\mathrm{kg} / \mathrm{m}^{3}\right)$ & 8700 & 2200 & 11370 & 1.2 & 2400 & 2400 & 2400 & 900 & 6.14 \\
\hline Specific heat $(\mathrm{J} /(\mathrm{kg} . \mathrm{k}))$ & 385 & 1900 & 3000 & 1005 & 830 & 1480 & 880 & 1257 & 96.6 \\
\hline
\end{tabular}


1.1 Proximity effect in the cables

\section{Results}

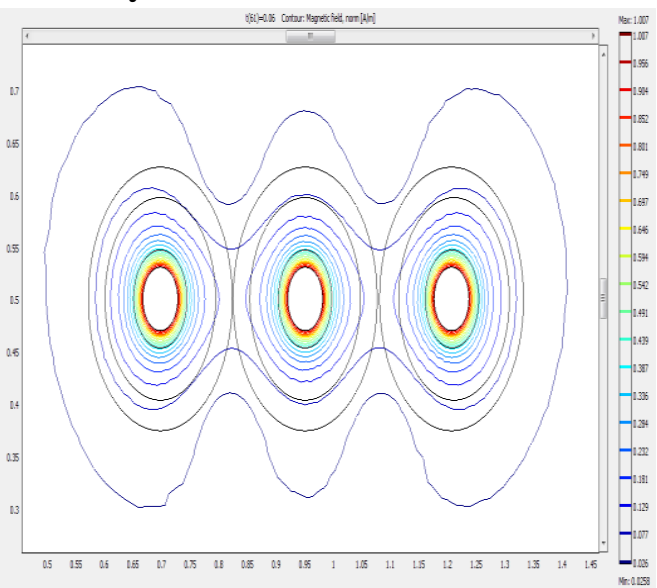

Fig 5: Magnetic field in cables with less spacing

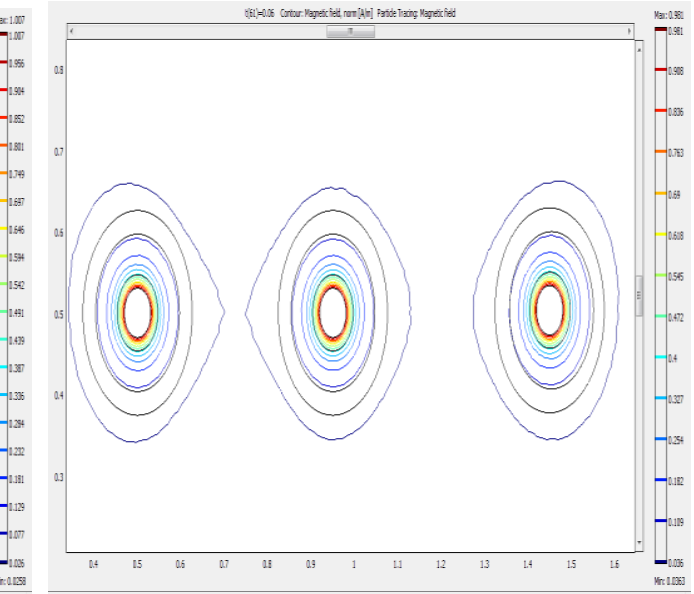

Fig 6: Magnetic field effect in cables with spacing

1.2 Thermal field distribution for a cable installed in air

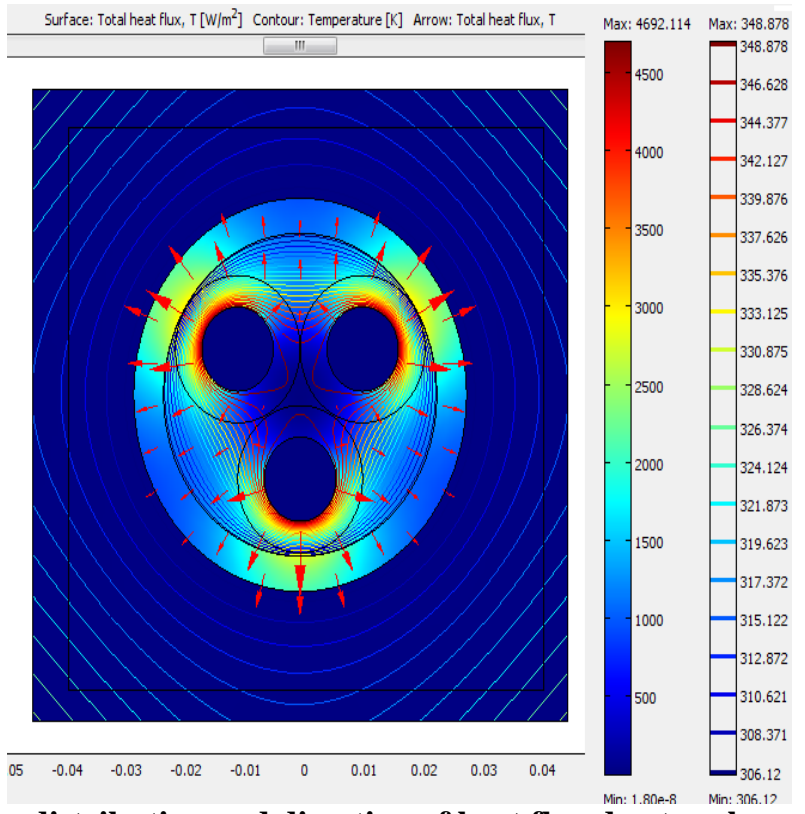

Fig 7: surface temperature distribution and direction of heat flux due to solar and wind effects
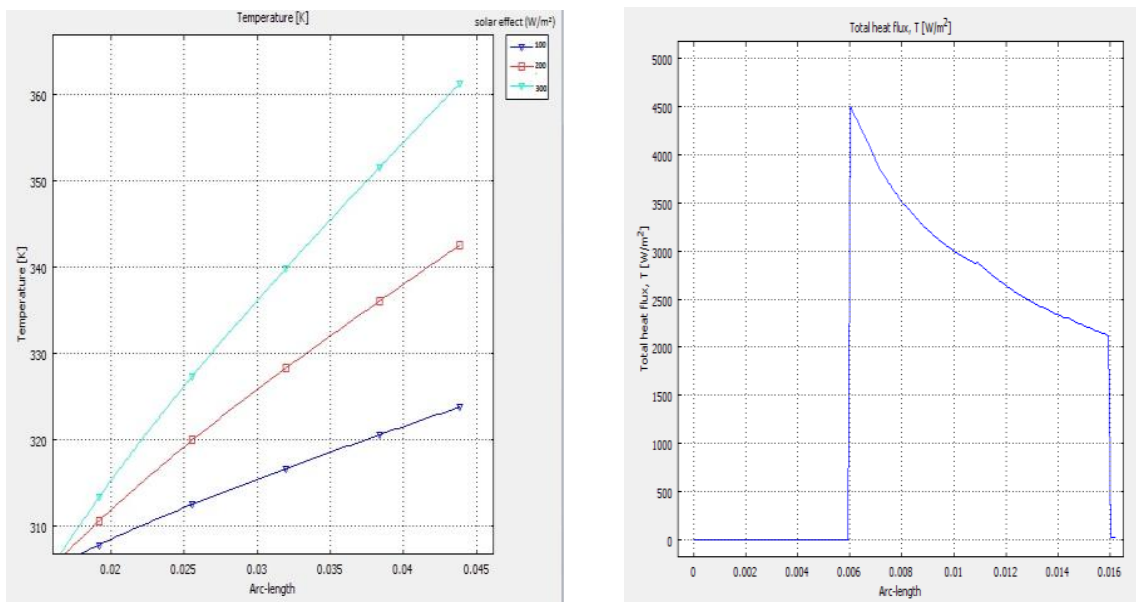

Fig 8: Temperature graph of cable installed in air Fig 9: Total heat flux graph of cable installed in air 
1.3 Temperature effect on a cable buried directly underground

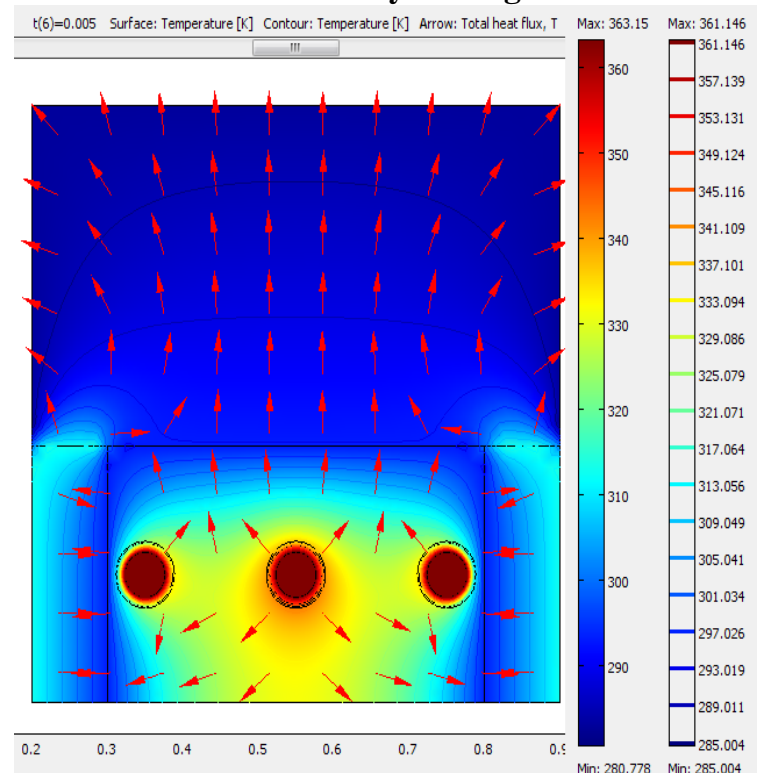

Fig 10: surface temperature distribution in the cable buried directly underground in trenches
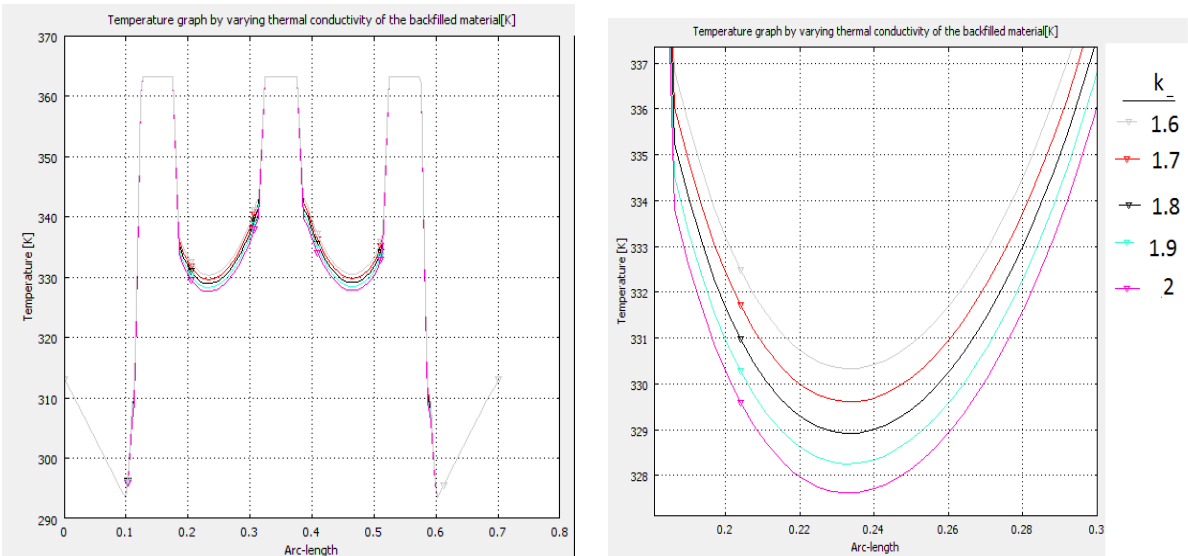

Fig 11: Temperature graph along cable axis Fig 12:Variation of temperature between two conductors 1.4 Heat flux distribution due to the presence of heat source underground

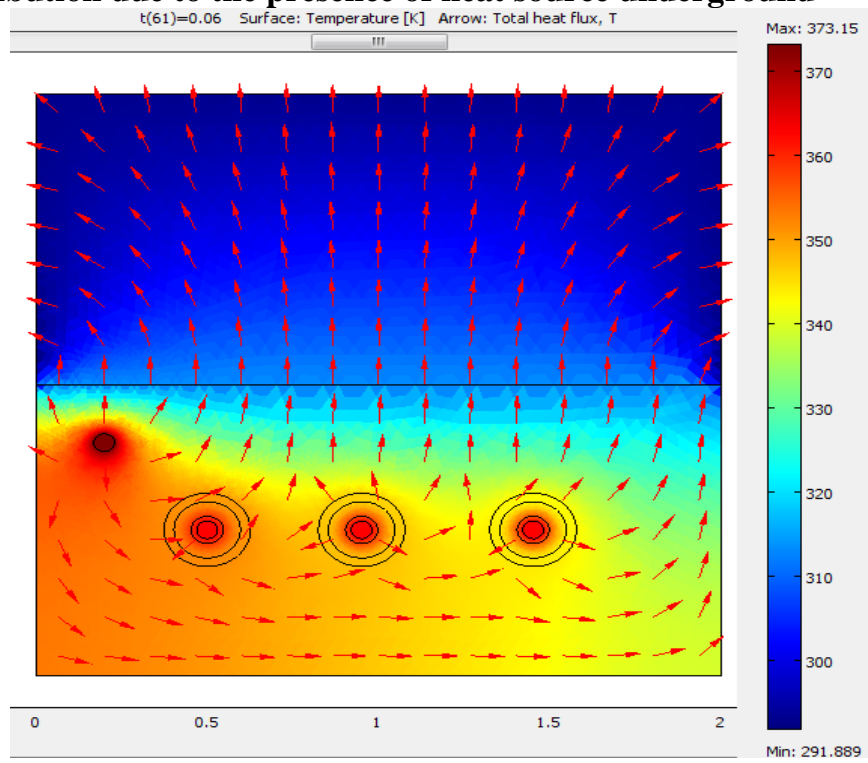

Fig 13: surface temperature distribution due to the effect of heat source underground 


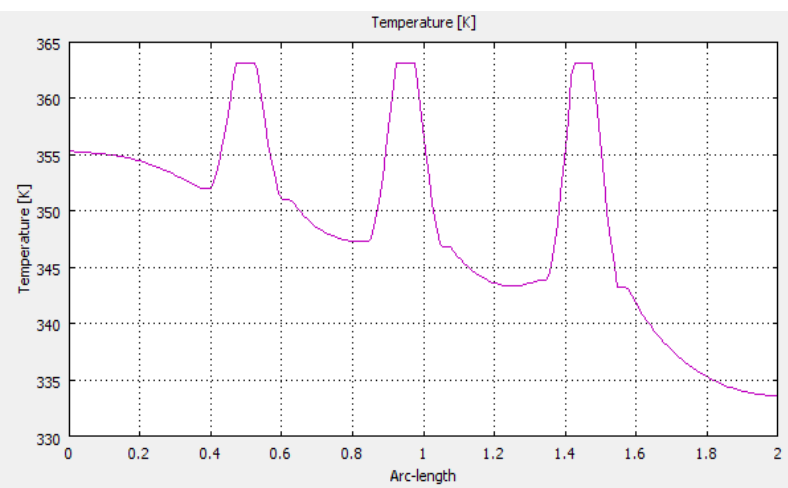

Fig 14: Temperature graph due to the effect of heat source underground 1.5 HEAT FLUX DISTRIBUTION IN DIFFERENT CABLES

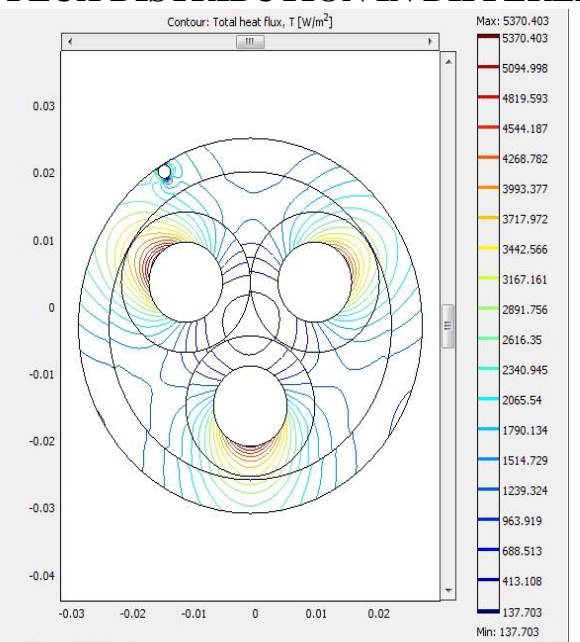

Fig 15: void filled with air

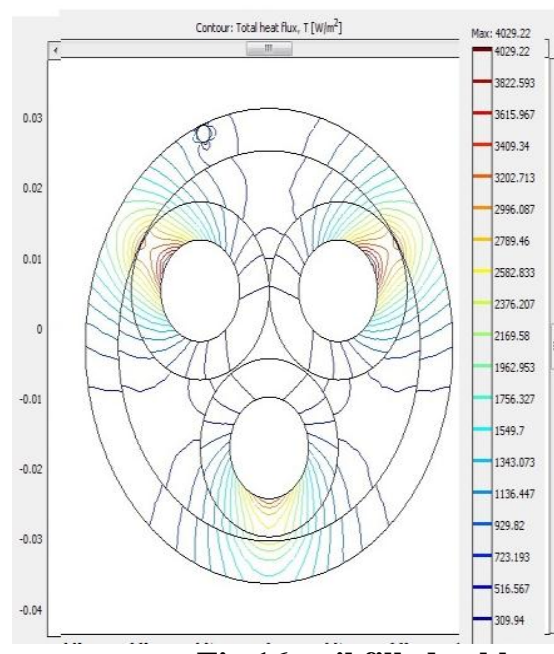

Fig 16: oil filled cable

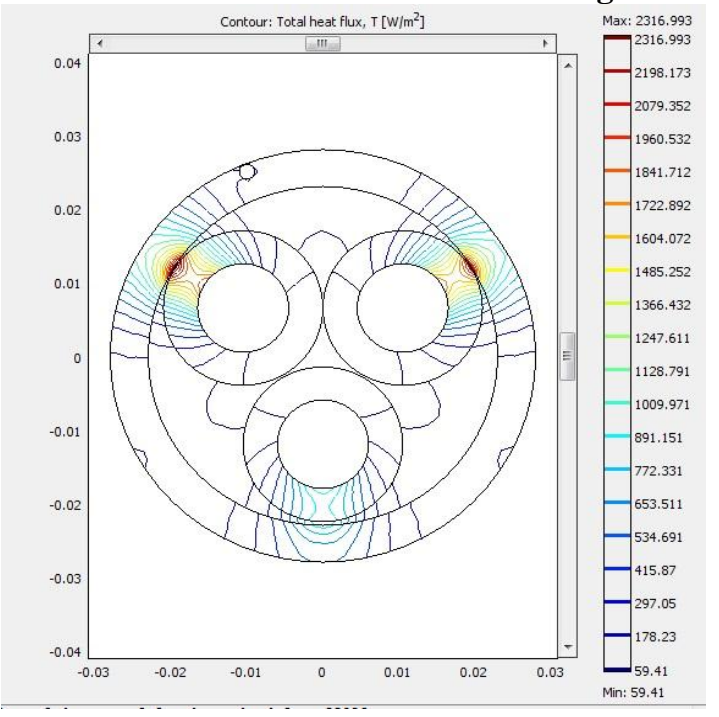

Fig 17: Gas filled cable

Table-II: Results

\begin{tabular}{|c|c|}
\hline filler & $\begin{array}{c}\text { Max total heat } \\
\text { flux }\left(\mathrm{W} / \mathrm{m}^{2}\right)\end{array}$ \\
\hline Air(void) & 5370 \\
\hline Oil & 4029 \\
\hline gas & 2316 \\
\hline
\end{tabular}




\section{Discussions}

The current in the cable induces certain amount of flux in the nearby cable producing eddy current loss which is shown by the magnetic field in Fig.5. As per standards when the spacing of $20 \mathrm{~cm}$ is provided between the cables, then the proximity effect is reduced which is shown in Fig.6. The cable has the effect due to heat when the solar energy is incident on the cable that is installed in air. Fig.7 shows the temperature distribution in the cable and the arrows represents the heat flux direction from high temperature zone to low temperature zone. By convection and radiation, heat is transferred by distribution of heat flux radial outwards. In the conductor heat is transferred by means of conduction. Fig. 8 shows the thermal effect on the cable due to the solar radiation effect which is considered as heat source of $100-300 \mathrm{w} / \mathrm{m}^{2}$. This causes the high temperature in the surrounding which affects the cable that is operating with in the breakdown limit of the insulation. Fig.9 shows the heat flux of a conductor in 3-core cable with zero value inside the conductor, max at the surface of the conductor and decreasing towards the sheath surface. Fig.10 and Fig.11 shows the temperature distribution when the cable is buried directly in the ground. Fig.12 shows the decrease in temperature when the thermal conductivity of the backfill material varies from k=1.6 to 2 for the moist soil. Fig. 13 and Fig. 14 shows the thermal effect on cable when a steam pipe is crossing over the cable. Fig. 15 to Fig. 17 shows the contour plot of heat flux. The results in the Table-II show that the heat generation in the cable will be reduced for gas filled cable rather than oil filled cable.

\section{Conclusion}

In this paper the cable modeled to show the thermal effects when it is placed in air, directly buried in trenches and the cable crossing over a heat source underground. The results show that the heat flux distribution in the cable by means of conduction, convection and radiation for a 3-core cable. Even with changing weather conditions the cable dissipation rate doesn't affect much which is due to the high conductivity of the backfill material.

\section{References}

[1]. Hanna, M. A., Chikhani, A. Y., \& Salama, M. M. A. (1994). Thermal analysis of power cables in multi-layered soil. III. Case of two cables in a trench Power Delivery, IEEE Transactions on, 9(1), 572-578.

[2]. Brandon, T. L., Mitchell, J. K., \& Cameron, J. T. (1989). Thermal instability in buried cable backfills Journal of Geotechnical Engineering, 115(1), 38-55.

[3]. Hanna, M. A., Chikhani, A. Y., \& Salama, M. M. A. (1993). Thermal analysis of power cables in multi-layered soil. I. Theoretical model Power Delivery, IEEE Transactions on, 8(3), 761-771.

[4]. Al-Saud, M. S., El-Kady, M. A., \& Findlay, R. D. (2008). A new approach to underground cable performance assessment Electric Power Systems Research, 78(5), 907-918.

[5]. Yanmu, L. I., et al. Coupled Electromagnetic-Thermal Modeling the Temperature Distribution of XLPE Cable, IEEE Power and Energy Engineering Conference, Asia-Pacific 2009,pp. 1-4

[6]. COMSOL Group Ltd., Stockholm, Sweden: Comsol Multiphysics Software Package Version 3.3a. December 2006. 